\title{
Mortality and important events: Another look
}

\author{
WILLIAM V. RAGO and MARK MASON \\ Texas Department of Mental Health and Mental Retardation, Austin, Texas 78705
}

and

\author{
CHARLES C. CLELAND \\ Department of Special Education, University of Texas, Austin, Texas 78712
}

\begin{abstract}
The "death dip/death rise" hypothesis in relation to important life events was reexamined using conventional and Schulz and Bazerman's (1980) methodological refinements. We studied 463 profoundly mentally retarded $(P M R)$ (mean $I Q=7)$ who died in Texas institutions. By using a sample in which psychological variables were unlikely to effect timing of death, we found no evidence for the "death dip/death rise" phenomenon for Christmas, Thanksgiving, date of institutionalization, or birthdays. Had a significant "death dip/death rise" effect occurred in our sample, then some endogenous rhythm would have been a compelling hypothesis. That such did not occur effectively refutes physiological variables. Overall, our results fail to support the validity of death dip and death rise phenomena.
\end{abstract}

"I'd like to live to be 100 " and "I'd like to live till my 60th wedding anniversary" are frequently heard comments. Such comments reflect the assumption that the "death dip/death rise" hypothesis in relation to important life events is anchored in a motivation to live. It has been theorized (Schulz, 1978) that this motivation for the prolongation of one's life emanates from a psychological perspective whereby one looks forward to something.

Schulz and Bazerman's (1980) "second look" at the mortality studies supporting the dual hypotheses of a "death dip" preceding a significant occasion and a "death rise" following the occasion indicates that such hypotheses do not withstand the close scrutiny of reanalysis. Yet, these researchers urge a certain degree of caution in interpreting the "death dip/death rise" literature. Although the methodological procedures they employed in their reanalysis of data previously presented as supportive of the phenomenon "flatten out" the distribution of deaths, a number of psychological variables may interact to make a forthright and clear interpretation of the results difficult.

It appears that the major source of this psychological confounding is inherent in the procedure common to most of the research related to the death dip phenomenon. The death data are usually grouped about an occasion that the researcher believes to have been significant in the lives of his subjects. Significant occasions may be birthdays, anniversaries, or religious holidays. An assumption underlying the grouping of this data is that the occasion under investigation is equally significant to all subjects. Further, such procedures imply that the extent of the significance is such that the subjects utilize some as yet undisclosed mechanism to prolong their life in order to be present for the occasion.
This assumption of psychological equivalence may be difficult to uphold. The significance of an event in an individual's life may be as difficult to determine as was the significance of the seemingly trivial utterance of "Citizen Kane" that provided the focal point of a great motion picture.

When grouping data around a common ceremonial occasion, there is the distinct possibility that psychological variables idiosyncratic to the subject result in the death distribution's achieving a uniformity that may actually mask the presence of a death dip/death rise phenomenon. When the researcher looks for the presence of this phenomenon around several apparently significant occasions, such as Morris' (1965) concern for birthdays or Phillips and Feldman's (1973) concern for national elections, the underlying suggestion is such as to reinforce our concern for psychological idiosyncracies as a determinate of time of death. Yet, it would seem to be a difficult, if not a methodologically impossible task, to individually control for the idiosyncracies of the subjects. As long as the subject is capable of attaching significance to his anticipation of the future, proper controls appear unlikely.

\section{RATIONALE FOR SUBJECT SELECTION AND DESCRIPTIVE CHARACTERISTICS}

Previous research on the death dip/death rise hypothesis have included samples of notable Americans and Orthodox Jews (Phillips \& Feldman, 1973), the very aged (Alderson, 1975), and mixed socioeconomic groups (Kunz \& Summers, in press). All subjects in previous research possessed, at minimum, normal intelligence, with the notable American sample representing the upper extremes of the intelligence curve. Since 
our intention in this study is to investigate the death dip/death rise hypothesis in a manner that virtually eliminates psychological variables, we have chosen as subjects the profoundly mentally retarded (PMR).

The PMR, whose intelligence quotients are 19 or below (Grossman, 1977), have been described as both "a-cultural and a-historic" (sic) (MacAndrew \& Edgerton, 1964 , p. 312). Speech is almost universally absent (Cleland, 1979), as is self-recognition (Harris, 1977; Pachacek, Cleland, \& Bell, 1973). Due to the tremendous burden the PMR present, most are institutionalized at an early age and remain so until death. As such, we can exclude to an extent impossible with normal subjects such concerns as birthdays, national elections, religious affiliation, anniversaries, and other psychological variables, since cognitive deficits are of such magnitude as to preclude subjects' even knowing when their birthdays occur. Our subjects, in effect, are the polar opposites of Phillips and Feldman's eminent Americans.

The subjects in our study were 463 PMR individuals who died while residents of a state school in Texas. Their IQ range extended from 1 to 19 , with a mean of 7.0. The average length of institutionalization was 12.1 years and ranged from less than 6 months to 57 years. The mean age at death was 43.4 years, with a range of 8.3-64.1 years. Approximately 60\% (278) of our sample were male, and 185 were females. We discovered no sex differences with regard to the data to be presented.

\section{BIRTH DATE AS A CEREMONIAL OCCASION IN THE PMR}

Our concern was with the distribution of deaths in a population lacking the intellectual ability to know a significant event. This psychological control permitted us to investigate the death dip/death rise hypothesis in a manner not possible with normal subjects.

Several conventionally accepted ceremonial occasions (i.e., Christmas, Thanksgiving, and birthday) were selected, and each was analyzed in two different ways On one hand, we followed the traditional manner and grouped our data into months. Once this analysis was performed, we then employed the Schulz and Bazerman (1980) procedure and grouped the data into 31-day intervals preceding and following the day of the ceremonial event. Since we used a special sample, we reasoned that another significant event might be the day the subjects were first admitted to the institution, and we included this day also. Thus, this ceremonial occasion functioned as a control for conventionally conceived days of importance. Since all analyses resulted in similar results, we present only the findings of the birthday analysis, from which we can generalize to the other dates.

Table 1 depicts the death distribution of PMR subjects grouped by months. Our concern was with the
Table 1

Number of Deaths Before, During, and After Birth Month

\begin{tabular}{|c|c|c|c|}
\hline \multicolumn{2}{|c|}{ Before Birth Month } & \multicolumn{2}{|c|}{ After Birth Month } \\
\hline $\begin{array}{c}\text { Number of } \\
\text { Months }\end{array}$ & $\begin{array}{c}\text { Number of } \\
\text { Deaths }\end{array}$ & $\begin{array}{c}\text { Number of } \\
\text { Months }\end{array}$ & $\begin{array}{c}\text { Number of } \\
\text { Deaths }\end{array}$ \\
\hline 6 & 44 & 1 & 37 \\
\hline 5 & 42 & 2 & 22 \\
\hline 4 & 33 & 3 & 39 \\
\hline 3 & 46 & 4 & 35 \\
\hline 2 & 37 & 5 & 43 \\
\hline 1 & 37 & & \\
\hline
\end{tabular}

Note-The number of deaths during the birth month $=48$; the total number of deaths $=463$.

Table 2

Number of Deaths Before, On, and After Birthday

\begin{tabular}{|c|c|c|c|}
\hline \multicolumn{2}{|c|}{ Before Birthday } & \multicolumn{2}{|c|}{ After Birthday } \\
\hline $\begin{array}{c}\text { Number of } \\
\text { Days }\end{array}$ & $\begin{array}{c}\text { Number of } \\
\text { Deaths }\end{array}$ & $\begin{array}{c}\text { Number of } \\
\text { Days }\end{array}$ & $\begin{array}{c}\text { Number of } \\
\text { Deaths }\end{array}$ \\
\hline $156-186$ & 47 & $1-31$ & 41 \\
\hline $125-155$ & 38 & $32-62$ & 32 \\
\hline $94-124$ & 38 & $63-93$ & 33 \\
\hline $63-93$ & 43 & $94-124$ & 40 \\
\hline $32-62$ & 39 & $125-155$ & 40 \\
\hline $1-31$ & 40 & & \\
\hline
\end{tabular}

Note-The number of deaths on the birthday $=2 ;$ the total number of deaths $=433$. There are 30 fewer subjects included in this table than are included in Table 1; the difference is due to the 24 days that are not represented in this table.

presence of a dip immediately prior to the birth month and a rise immediately after. Simple observation showed clearly that the numbers of deaths 1 month before and after the birth month are equal $(\mathrm{N}=37)$. Statistical analysis confirmed that these frequencies failed to differ from chance. In fact, the lowest frequency of deaths occurred in the 2nd month after the birth month, a finding at odds with the hypothesis investigated.

We then took the data in Table 1 and grouped it according to the "more sensitive method" of Schulz and Bazerman (1980) and obtained the distribution found in Table 2 . When these data are examined for the presence of a dip or a rise, it is obvious neither exists. In the 1- to 31-day period immediately prior to the birthday, 40 subjects died, whereas in the same period immediately following the birthday, 41 subjects died. Statistical tests performed failed to find a difference between the form of the distribution in Table 2 and a uniform distribution that would be expected by chance, given the equal (31-day) intervals.

Although the numbers differed, when contrasting Table 1 with Table 2, it was apparent that there was no evidence of either a death dip or a death rise. In a sample in which controls for the attachment of significance to important events exists, we found no support for the hypothesis investigated. 


\section{DISCUSSION}

Our intent was to study the death dip/death rise hypothesis in a population in which we could reasonable sidestep the presence of psychological variables. In the PMR we submit this psychological control is inherent in the subjects.

In analyzing time of death in the PMR across four "ceremonial" occasions (i.e., Christmas, Thanksgiving, date of institutionalization, and birth date), we failed to discover any evidence suggesting the presence of either a death dip or a death rise. In this regard, our data on birth dates conformed nicely to similar analyses performed by Schulz and Bazerman (1980) on eminent Americans.

These researchers reanalyzed Phillips and Feldman's (1973) data and found little support for the death dip/death rise hypothesis. Our attention to their findings focused on what we termed the psychological equivalence assumption that seemed to be inherent within the methodology of grouping death data around a specific event. Although our study cannot address the problem of psychological equivalence directly, we did "a best approximation." The birthday analysis of Phillips and Feldman was performed on eminent Americans; ours was performed on the PMR, a diametrically opposite population. With this in mind, we performed an F test (Young \& Veldman, 1972) in which the variance of the PMR data was compared with that of the eminent Americans as these data were reanalyzed by Schulz and Bazerman (1980). That the result of such an analysis was nonsignificant suggested that the two distributions might arise from the same population. If this is so, we may further assume that the data as analyzed by Schulz and Bazerman were analogous to those analyzed in the PMR, in that we may dismiss the problem of psychological equivalence. This would imply that the flat distribution found in the reanalysis of the time of death of eminent Americans is a fair test of the death dip/death rise hypothesis and does not result from an inability to control for psychological equivalence.

When there is little concern for psychological variables confounding the distribution, there is no hint of a death dip/ death rise. Had our data revealed a significant death dip/death rise, then some biological process would have appeared equally as plausible as psychological causation. However, no such results obtained, but should future research document the existence of the death dip/death rise phenomenon, something our research casts in doubt, the cause most likely would not be some endogenous patterning, or else it should have been revealed in our PMR data.

\section{REFERENCES}

Alderson, M. Relationship between month of birth and month of death in the elderly. British Journal of Preventive and Social Medicine, 1975, 29, 151-156.

Cleland, C. C. The profoundly mentally retarded. Englewood Cliffs, N.J: Prentice-Hall, 1979.

Grossman, J. H. (Ed.). Manual on terminology and classification in mental retardation (rev. ed.). Washington, D.C: American Association on Mental Deficiency, Special Publication Series, 1977.

HarRIs, L. T. Self-recognition among institutionalized profoundly retarded males: A replication. Bulletin of the Psychonomic Society, 1977, 9, 43-44.

Kunz, P. R., \& Summers, J. A time to die: A study of birthdays and time of death. Omega: Journal of Death and Dying, in press.

MacAndrew, C., \& Edgerton, R. B. The everyday life of institutionalized "idiots." Human Organization, 1964, 23, 312-318.

Morris, R. B. (Ed.). Four hundred notable Americans. New York: Harper \& Row, 1965.

Pachacek, T., Cleland, C. C., \& Bell, K. Self-recognition in profoundly retarded males. Bulletin of the Psychonomic Society, 1973, 1, 327-330.

Phillips, D. P., \& Feldman, K. A. A dip in deaths before ceremonial occasions: Some new relationships between social integration and mortality. American Sociological Review, 1973, 38, 678-696.

Schulz, R. The psychology of death, dying and bereavement. Reading, Mass: Addison-Wesley, 1978.

Schulz, R., \& Bazerman, M. Ceremonial occasions and mortality. American Psychologist, 1980, 35, 253-261.

YounG, R. K., \& VeLdMAN, D. J. Introductory statistics for the behavioral sciences. New York: Holt, Rinehart, \& Winston, 1972.

(Received for publication January 30, 1981.) 